\title{
Epidemiology and Public Health Aspects of Animal Biting in Shush County, Khuzestan Province, Iran
}

\author{
Mohammad Hossein Feizhaddad ${ }^{1}$; Hamid Kassiri $^{2, *} ;$ Masoud Lotfi $^{2}$; Seyedeh Sahar Hoseini ${ }^{2}$ \\ ${ }^{1}$ Department of Medical Parasitology, Ahvaz Jundishapur University of Medical Sciences, Ahvaz, IR Iran \\ ${ }^{2}$ Department of Medical Entomology and Vector Control, Ahvaz Jundishapur University of Medical Sciences, Ahvaz, IR Iran \\ ${ }^{*}$ Corresponding author: Hamid Kassiri, Department of Medical Entomology and Vector Control, Ahvaz Jundishapur University of Medical Sciences, Ahvaz, IR Iran. Tel:+98-6113738269, \\ Fax:+98-6113738282, E-mail: Hamid.Kassiri@yahoo.com
}

Received: March 5, 2014; Revised: September 20, 2014; Accepted: September 23, 2014

\begin{abstract}
Background: Animal bites, especially dog bites, are common health problems which are rarely addressed. It is estimated that 15 million people are bitten by animals worldwide annually. Diseases caused by animal bites are problematic matters in the world as well as in Iran. The main disease caused by animal bites is rabies. Rabies is a fatal acute viral disease causing inclusive symptoms in the central nervous system in domestic and wild carnivores. Humans and other warm-blooded mammals are often randomly involved with an infected animal bite.

Objectives: Due to the increasing number of cases of animal bites in the County of Shush (southwestern Iran) because of its geographical status as a farming-animal husbandry region as well as the residents that are more exposed to animal bites, this study was designed to investigate the epidemiology and prevalence rate of animal bites in this county during 2000-2004.

Materials and Methods: In this descriptive cross-sectional research, a particular questionnaire was filled out for all the cases. The questionnaire included questions about demographic and epidemiologic characters such as, occupation, sex, age, biting animal type, treatment type, bite site, etc. Data analysis through SPSS and Excel software was performed and the percentages and mean of statistical figures were determined. Finally, descriptive statistics was used in the forms of tables and graphs to summarize the data.

Results: Findings of this study indicated that the average prevalence of animal bites during the above five years was 1.3 per 1000 population and there was an increased trend in the prevalence rate of animal bite in this county. During these five years, a total number of 1300 cases of animal bites were recorded: males 971 (74.7\%) and females 329 (25.3\%). The numbers of animal bites in rural and urban areas were 1061 (81.6\%) and 239 (18.4\%), respectively. Therefore, a 4.4-time rate of animal bites was recorded for rural areas. Moreover, the majority of animal bites (31.9\%) were determined in the age group of 10-20. In terms of employment, students with 390 cases (30\%) comprised the highest work-related group. From the viewpoint of bite site, the most prevalent biting site was feet with 907 cases (69.7\%), followed by hands with 236 (18.2\%) cases, while only one bite was recorded on the neck area. Totally, $95.8 \%$ of bites were confirmed to be applied by dogs; however, cats were responsible for only 3.3\% of bites. During the five years of the study, 155 stray dogs in rural areas and 84 in urban areas were hunted.

Conclusions: Due to the demographic status of Shush County, its high rural population engaged in agriculture and livestock farming, keeping dogs at home for job demands and a great percentage of animal bites among students, educational programs for students in schools and for farmers should be prioritized regarding first aid for prevention of animal biting.
\end{abstract}

Keywords:Epidemiology; Animals; Bites; Prevalence; Rabies; Iran

\section{Background}

Animal bites are a significant threat to human health because of the fatality of subsequent infections such as rabies. Although animal bites are preventable, they are still a health problem in many countries, especially in Asia and Africa. Every year, more than 15000000 people receive post-exposure prophylaxis, mostly in China and India. More than 55000 people die of rabies every year, mostly in Asia and Africa. About 40\% of people who are bitten by suspect rabid animals are children under 15 years old $(1,2)$.
In terms of epidemiology, rabies is found in domestic and sylvatic forms. The disease is common in most areas of Asia, Africa and small parts of North America and South America. Rabies is common in both domestic and sylvatic forms in most provinces and counties of Iran (3). Rabies is endemic in Iran and occurs frequently in domestic animals (4-6). The annual Increase of animal bites can enhance the costs due to importing anti-rabies vaccines and serums. Furthermore, rabies has a high fatality rate; thus, after the appearance of clinical symptoms in

Copyright ( ) 2014, Infectious Diseases and Tropical Medicine Research Center; Published by Kowsar. This is an open-access article distributed under the terms of the Creative Commons Attribution-NonCommercial 4.0 International License (http://creativecommons.org/licenses/by-nc/4.0/) which permits copy and redistribute the material just in noncommercial usages, provided the original work is properly cited. 
humans or in animals it is not curable and death is almost inevitable $(7,8)$.

The main infection reservoirs in different geographical areas vary in wildlife, which are important reservoirs for rabies transmission. In the United States, Skunk (in the west), fox (in the east) and raccoon (in Florida) are the main reservoirs for rabies (9). Dogs have the most important role in transmission of rabies to humans (2). Dog bite, in addition to bacterial infections, can transfer rabies, tetanus and tularemia and cat bite may cause transmission of rabies and tetanus. Being bitten and scratched by cat can also transfer Bartonella henselae (causing cat scratch disease) and Francisella tularensis (causing tularemia) (10).

In the northern region of Iran, dogs and foxes and in west and north-west of the country wolves are the most important disease vectors and reservoirs. Previous studies showed that the cause of rabies has not been isolated from bats in Iran $(11,12)$. In many studies, animal bites have been reported for different age groups. According to the World Health Organization reports, most cases of human rabies have been occurred in boys under 15 years old as well as in 40\% of patients aged 5-14 (13). With an exceptional in Pandey's study on foreign residents and tourists in Nepal which indicated that more females than males were bitten by a rabid animal, in other studies the animal bite cases have been higher for males (14).

In general, many factors must be considered for rabies control campaign plans and the first act is surveillance and epidemiologic data gathering. One of the main concerns in relation to prevention and control of this disease is the lack of consistent care and regular reporting by health centers. In this context, this shortcoming has led to unavailability of accurate, adequate and timely information for the abovementioned issues. Therefore, community participation and cooperation should be granted for successfulness of the above responsibilities.

\section{Objectives}

Given the high rate of rural population in the County of Shush, keeping dogs in homes and the increased incidence rate of animal bites in recent years, it persuaded the authors to perform an epidemiological study on animal bites in this region. The present study could offer the approaches for controlling diseases and reducing animal bites in Shush County.

\section{Materials and Methods}

The study population included all the individuals who had been bitten by animals during 2000-2004 and referred to animal bites vaccination centers of Shush County, Khuzestan province, southwestern Iran. In this descriptive research, a special questionnaire was filled out for all the cases with animal bites. The questionnaire included questions about demographic and epi- demiologic features such as, occupation, sex, age, biting animal, treatment regimen, bite site, etc. Data analysis through SPSS and Excel software was performed and percentages and mean of statistical figures were determined. Finally, descriptive statistics was used in the form of tables and graphs to summarize the data. The ethical principles of this research were investigated and discussed in the Research Committee of Medical Entomology Department and required modifications were made, faced to be approved.

\section{Results}

The results showed that 1300 cases with animal bites in rabies vaccination centers had been recorded during 2000-2004. The average prevalence rate of animal biting in Shush County during the above five years was approximately 1.3 per 1000 population. There was almost an increased prevalence rate for animal biting over the five years with $1.22,1.17,1.11,1.53$ and 1.47 per 1000 population, for each year, respectively. Figure 1 shows the trend of animal bite cases during the study period. Depending on the age group, the results showed that the frequency of cases with animal bites in the 10-20-year age group (31.9\%) was more than other age groups and the lowest rate was observed in children under four years old (3.6\%) (Figure 2).

Regarding the time of bites, December (10\%) was recorded for most of the cases; however, the lowest rates were traced in January (4.8\%) (Table 1). Seasonally, cases with animal bites were documented in autumn (26.8\%), winter (25.2\%), summer (24.1\%) and spring (23.9\%), respectively (Table 1). The findings from this study indicated that cases with animal bites during 2000-2004 and for all the months were higher in males than in females. During these five years, a total of 1300 animal bites in both genders were recorded with 971 (74.7\%) in males and 329 (25.3\%) in females. According to the results extracted from Table 1, the animal bite rate in males was approximately 2.9 times more than females.

Throughout 2000-2004, around 81.6\% of animal bites occurred in rural areas in Shush County, which were 4.4 times more than urban areas (18.4\%). From the bite site point of view (on the body), 907 cases (69.7\%) were documented for feet and the subsequent bite sites were: hands, trunks, heads-faces and necks, respectively (Figure 3). From the occupation viewpoint, the most cases of animal bites were students (30\%) and the least were ranchers (2.1\%) (Figure 4).

During 2000-2004, 98\% of cases were treated against rabies by noncompleted prophylaxis treatment regimens, while complete prophylaxis regimens were only documented for $2 \%$ of cases. Based on the research findings in Table 2, during 2000-2004 the majority animal bites occurred by dogs (95.8\%), followed by cats (3.3\%); two animal bites occurred by wolves, eight by jackals and three by foxes. During this period, 155 stray dogs in rural areas and 84 in urban areas were hunted. 
Feizhaddad MH et al.

Table 1. Prevalence of Cases With Animal Bites by Month and Sex in Shush County, Khuzestan Province, Southwestern Iran ${ }^{\text {a }}$

\begin{tabular}{lccc}
\hline \multirow{2}{*}{ Month } & \multicolumn{2}{c}{ Gender } & \multirow{2}{*}{ Total } \\
\cline { 2 - 3 } & Female & Male & \\
\hline April & $17(17.9)$ & $78(82.1)$ & $95(7.3)$ \\
May & $37(31.6)$ & $80(68.4)$ & $117(9.0)$ \\
June & $28(28.3)$ & $71(71.7)$ & $99(7.6)$ \\
July & $25(22.45)$ & $86(77.5)$ & $111(8.5)$ \\
August & $29(26.4)$ & $81(73.6)$ & $110(8.5)$ \\
September & $26(28.3)$ & $66(71.7)$ & $92(7.1)$ \\
October & $30(27.8)$ & $78(72.2)$ & $108(8.3)$ \\
November & $24(21.6)$ & $87(78.4)$ & $111(8.5)$ \\
\hline December & $25(19.4)$ & $104(80.6)$ & $129(10.0)$ \\
January & $20(24.8)$ & $82(80.4)$ & $102(7.8)$ \\
February & $28(24.8)$ & $85(75.2)$ & $113(8.7)$ \\
\hline March & $40(35.4)$ & $73(64.6)$ & $113(8.7)$ \\
\hline Total & $239(25.3)$ & $971(74.7)$ & $1300(100)$ \\
\hline a & & &
\end{tabular}

a Data are presented as No. (\%).

Table 2. Frequency Distribution of Cases With Animal Bites by the Biter Animals in Shush County, Khuzestan Province, Southwestern Iran ${ }^{\mathrm{a}}$

\begin{tabular}{lccccc}
\hline \multirow{2}{*}{ Year } & \multicolumn{5}{c}{ Biting Animal } \\
\cline { 2 - 6 } & Dog & Cat & Wolf & Jackal & Fox \\
\hline $\mathbf{2 0 0 0}$ & $228(93.1)$ & $12(4.9)$ & $1(0.4)$ & $2(0.8)$ & $2(0.8)$ \\
$\mathbf{2 0 0 1}$ & $227(97.0)$ & $5(2.1)$ & $1(1.5)$ & $1(1.5)$ & $0(0.0)$ \\
$\mathbf{2 0 0 2}$ & $211(95.7)$ & $9(4.1)$ & $0(0.0)$ & $0(0.0)$ & $1(4.5)$ \\
$\mathbf{2 0 0 3}$ & $293(97.3)$ & $10(3.3)$ & $0(0.0)$ & $3(4.3)$ & $0(0.0)$ \\
$\mathbf{2 0 0 4}$ & $286(97.3$ & $6(2.0)$ & $0(0.0)$ & $2(2.7)$ & $0(0.0)$ \\
Total & $1245(95.8)$ & $42(3.3)$ & $2(0.1)$ & $8(0.6)$ & $3(0.2)$ \\
\hline a Data are presented as No.(\%).
\end{tabular}

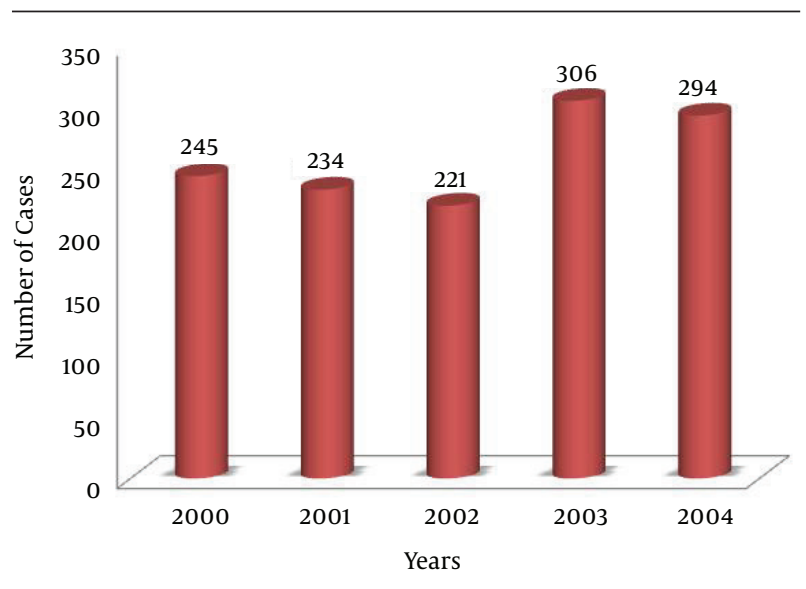

Figure 1. Trend of Animal Bites Frequency in Shush County, Khuzestan Province, Southwestern Iran

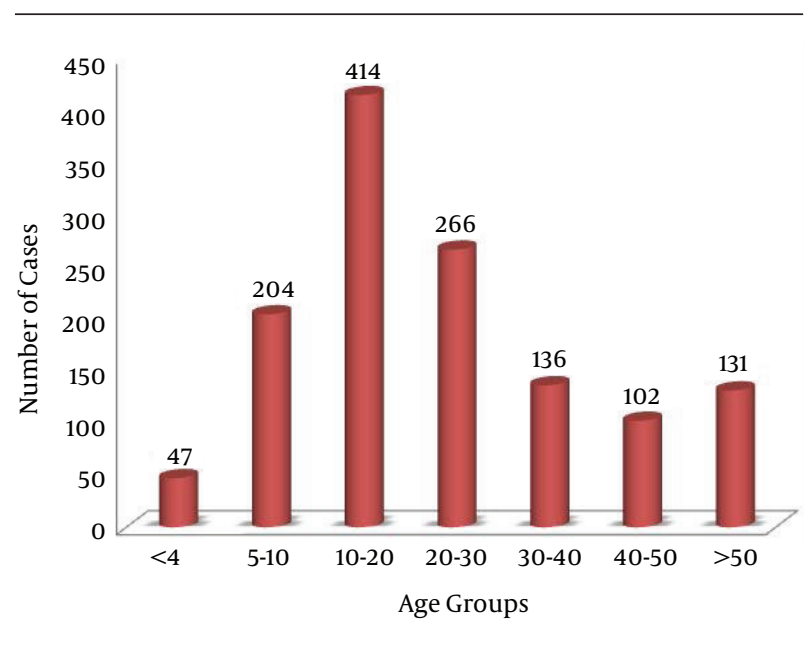

Figure 2. Age Distribution of Cases With Animal Bites in Shush County, Khuzestan Province, Southwestern Iran

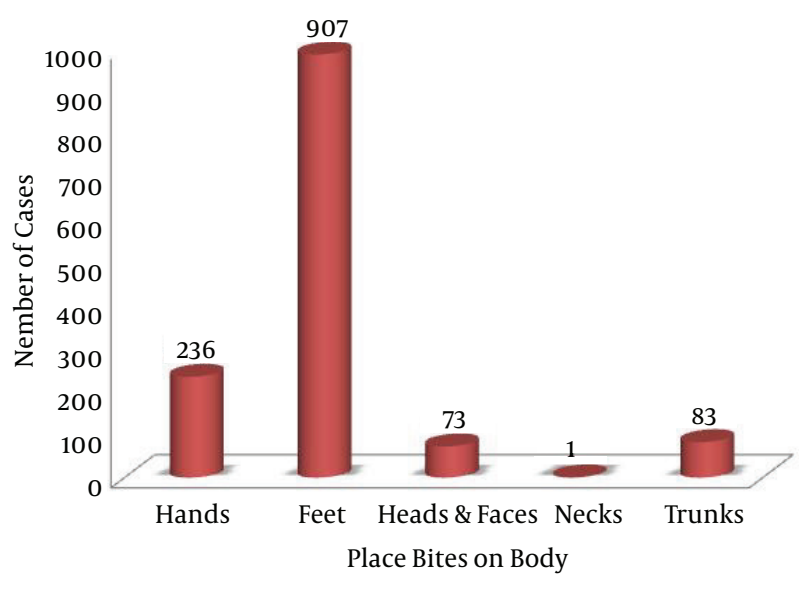

Figure 3. Distribution Frequency of Cases With Animal Bites by Bite Sites on the Body, Including Feet, Hands, Trunks, Heads-Faces and Necks in Shush County, Khuzestan Province, Southwestern Iran

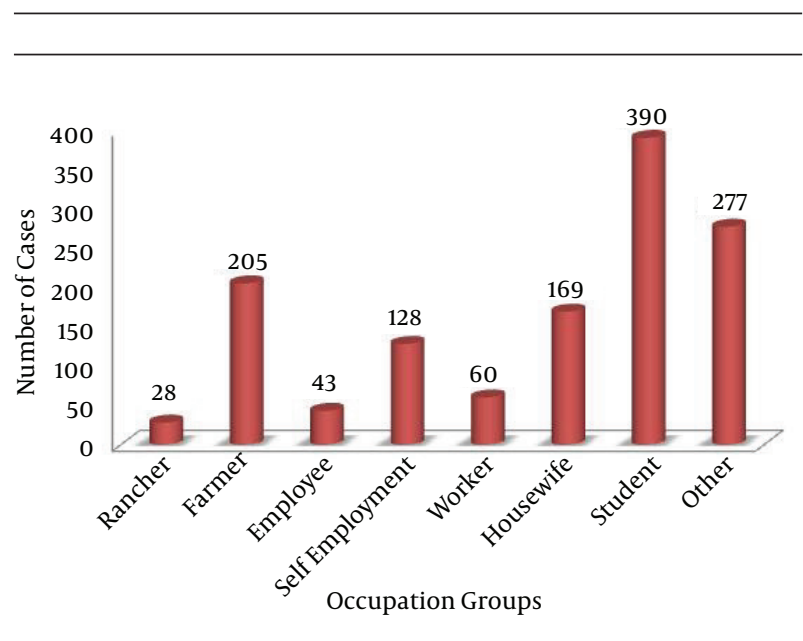

Figure 4. Frequency Distribution of Cases With Animal Bites by Occupation in Shush County, Khuzestan Province, Southwestern Iran 


\section{Discussion}

According to a research conducted by the Center for Reference and Research on Rabies, Pasteur Institute of Iran, cases of rabies have increased from 29860 people in 1990 to 93216 in 2002 (11). The World Health Organization has estimated that annually about 35000 cases of human rabies occur in the northern hemisphere, considering the fact that nearly half the world population live in this hemisphere. Furthermore, every year, about 10 million people are being covered by preventive measurements after animal bites (3). According to another report from Iran, the antirabies treatments have increased from 57070 cases in 1996 to 65632 cases in 1998 (15). Although, part of the increased number of animal bites could be due to the boost up in the country population; however, the increase was also evident in the number of standard bites per 100000 population. Other causes of increased human bite records by health centers could be due to increased people awareness, improved surveillance systems and higher accuracy of records.

There is a natural resistance to rabies in many animals, including humans, which could be achieved to some extend through genetic less sensitivity to the disease and by inactivated rabies vaccine, through both humeral and cellular immunity. Due to the rabies short incubation period, in a patient that refers 72 hours after the bite occurrence to prevent the disease, injectable anti-rabies immunoglobulin is ineffective, especially for cases with head and neck bites (16). Rabies is incurable and death is certain after the onset of clinical symptoms. However, the use of serum and vaccine as early as within 12 hours after a bite by a rabid animal can be quite effective (17).

This study was carried out on cases with animal bites, who referred to vaccination centers during 2000-2004 in Shush County, Khuzestan province, Southwestern Iran. The majority of animal bites (31.9\%) were observed in the age group of 10-20. Majidpour's study in Ardabil province indicated that most victims (44.13\%) were in the age group of 10-29 years old and the highest incidence rate (6.63) was in the age group of 30-50 (1). In the study of Zeynali et al. half of the victims belonged to the age group of 10-29 (18). Tepsumethanon et al. in their study on mammalian bites in Thailand showed that $42.3 \%$ of animal bites occurred in the age group of 10-14 and 39.7\% in the age group of 5-9 (19). The study of Pandey et al. showed that children were at a higher risk for head and face bite injuries (14). Singh et al. in India showed that the incidence rate of animal bites in the age group of 5-14 was high (20). Another study showed that the mean age for animal bites was 6.7 years old among children under 14 (21). In contrary, a study conducted in Pennsylvania, the USA, found different results and inconsistency with other studies, so that the highest incidence rate was reported in children under five years old (324/100000) (22). The World Health Organization has stated that the majority of human rabies cases has occurred in boys under 15 years old, of which 40\% aged 5-14 years old (13).
The five years of study indicated that 971 (74.7\%) and $329(25.3 \%)$ cases of animal bites occurred in males and females, respectively. The current study showed that the animal bites rate for males was three times more than that of females. Except for Pandey et al. study on foreign residents and tourists in Nepal in which more females than males were bitten by rabid animals (14), other studies reported that more females than males were exposed to animal bites. The obtained results from the current study were also consistent with references 18, 20, 22.

In the present study, doges were responsible for 1245 (95.8\%) cases of animal bites, which was in accordance with the results obtained from other studies. In the study of Majidpour et al. in Ardabil Province, Iran, doges were in charge of the majority of cases (96\%). The present research and Majidpour's study (1) revealed that rates of dog bites were $10 \%$ higher in comparison to other studies from different regions of Iran (18). A research in Srilanka showed that $95-97 \%$ of patients with rabies were infected by dog bites (23).

In this study, the majority of animal bites (81.6\%) occurred in rural inhabitants. A study by the Iranian Institute of Pasteur on 136 patients who died because of rabies showed that the highest percentage of deaths (30\%) were in the 10-19 age group, comprised of males (77\%) and rural inhabitants (83\%), and in $68 \%$ of cases dog was in charge (24). Sadeghi et al. in West Azerbaijan province documented that $63.4 \%$ of bites occurred in males, $35 \%$ in 10 19 age group, and $81.6 \%$ in rural areas, and $93.7 \%$ of cases were bitten by dogs (25). The results of this study, as well as the ones by the Pasteur Institute of Iran and Sadeghi had an undeniable attunement. Due to the high incidence of animal bites by dogs in urban and rural communities in Shush County, the need for fighting against stray dogs would be doubled.

In the present study, the main bite site of the body was foot. Of 1300 victims of animal bites, in 907 cases (69.7\%) feet were the most common bitten sites. Furthermore, Tepsumethanon et al. in their study showed that the most common injury sites on body were feet (56.6\%) (19), other investigations in this field have come up with similar findings (23). Household and domestic dog bites in children proved to have higher rates for facial trauma (14, 26). Majidpour et al. study on 4331 cases of animal bites in Ardabil province showed that 3078 of cases (71.79\%) were bitten in feet (1). In addition, a study on animal bites in Kerman province reported that the most affected sites of the body were feet (47\%), hands (41\%), trunks (7\%), heads and faces (3\%), and necks (2\%) (27).

In the present study, rates of animal bites in spring, summer, autumn and winter were $23.9 \%, 24.1 \%, 26.8 \%$ and $25.2 \%$, respectively. Majidpour's study on animal bites showed that most of the cases occurred in summer and seasonal distribution of animal bites was $28.3 \%$ in spring, $29.6 \%$ in summer, $20.8 \%$ in autumn and $21.2 \%$ in winter (1). However, in Sadeghi et al. study, most cases of bites (39.4\%) occurred in spring and the lowest (16.4\%) occurred 
in autumn (25). The present study recorded the most animal bites for December (10\%), May (9\%), February (8.7\%) and March (8.7\%), while the lowest rates were for January (4.8\%), September (7.1\%) and April (7.3\%), correspondingly. In West Azarbaidjan province in 2000, most of the cases with animal bites (24.4\%) occurred in May and the lowest rate (4.8\%) was in November (25). The study of animal bites in 2000 in Ardabil province showed that most of the cases were recorded for August, November, December and September, respectively (1).

The results from the present study confirmed that in terms of occupation, students (30\%) and farmers (15.8\%) had higher rates of animal bite injuries. In this regard, the findings were consistent with Zeynali et al. study (18). The statistics in Majidpour's study showed 29.1\% for students, $18.9 \%$ for farmers, $12.71 \%$ for housewives, $8.64 \%$ for ranchers, $8.9 \%$ for labors, and only $4 \%$ for government employees. While, Sadeghi et al. reported that 1871 of cases of animal bites (48\%) occurred in students (25). Commonly, in Shush, Ahvaz and Islam-Abadgharb, studies showed that the most animal bites occurred in students (28-30).

Lack of surveillance systems and shortage of in regular reporting are the major impediments associated with prevention and control of animal bites. The above defects have resulted in incorrect and insufficient information at proper time to tackle the issue. However, in this regard, collaboration and participation should be provided to public to ease the problem. In addition, it is necessary to promote public awareness, so that cases with animal biting are referred to health centers for treatment on time. Furthermore, the increased intersectoral coordination and planning should be performed for elimination of stray dogs and vaccination of domestic dogs.

\section{Acknowledgements}

Authors wish to express their sincere thanks to all the staff of health centers of Shush County, Khuzestan province, especially Mr. Babak Shakarami who sincerely helped with data collection.

\section{Funding/Support}

This project was financially supported by the Chancellor for Research Affairs of Ahvaz Jundishapur University of Medical Sciences, project No. $88 \mathrm{~S} 45$.

\section{References}

1. Majidpour A, Arshi S, Sadeghi H, Shamshirgaran SM, Habibzadeh S. [Animal bites: epidemiological considerations in Ardabil Province, 2000]. J Ardabil U of Med Sci \& Health. 2004;3(10):39-44.

2. World Health Organization . Rabies .. Available from: http://www. who.int/rabies/en/.

3. World Health Orgaganization . WHO Expert Consultation on Rabies, 1st Report. Geneva:WHO Technical Report Series; 2005.

4. Zeinali A, Tajik P, Rad MA. [Wild life diseases]. Donyaye Andisheh. 2002;4:53.

5. Nadin-Davis SA, Simani S, Armstrong J, Fayaz A, Wandeler AI. Molecular and antigenic characterization of rabies viruses from
Iran identifies variants with distinct epidemiological origins. Epidemiol Infect. 2003;131(1):777-90.

6. Hoboobati MM, Dehghani MH, Sarvat F. [A ten years record of animal bite cases of patients referred to Nikoopour health center, Yazd, 1990-1999]. J Shahid Sadoughi U Med Sci and Health. 2002; 9 (4):117-20.

7. Toogeh G, Sharifian R, Lak M, Safaee R, Artoni A, Peyvandi F. Presentation and pattern of symptoms in 382 patients with Glanzmann thrombasthenia in Iran. Am J Hematol. 2004;77(2):198-9.

8. Azizi F, Janghorbani M, Hatami H. [Epidemiology and control of common disease in Iran]. 2 edTehran: Khosravi Pub; 2010.

9. Hatami H, Razavi M, Eftekhar Ardebili H, Majlesi F, Nozadi M, Parizadeh MJ. 3 edTehran: Arjmand Pub; 2012.

10. Abrahamian FM, Goldstein EHC. Microbiology of animal bite wound infection.. Available from: http://cmr.asm.org.

11. Simani S. [Rabies situation in Iran]. $J$ Veterinary Faculty . 2003;58(3):275-8.

12. Shariati A. [Epidemiology of rabies in Khorasan state during 1994- 2003]. [Prevention of Veterinary Diseases].. Tehran: Tehran University Publication; 2004. p. 90.

13. Brillman JC, Sueanzer RW. Infections in emergency medicine. 2 edPhiladelphia: Lippiacott Raven Pub; 1998.

14. Pandey P, Shlim DR, Cave W, Springer MF. Risk of possible exposure to rabies among tourists and foreign residents in Nepal. $J$ Travel Med. 2002;9(3):127-31.

15. Simani S. [Rabies disease].Tehran: Iranian Pasteur Institute Pub; 2004.

16. Hanlon C, Corey L. Rabies virus and other Rhabdoviruses. In: Fauci A, Braunwald E, Kasper D, Hauser S, Longo D, Jameson J, et al editors. Harrison's Principles of Internal Medicine. 17 ed. New York: Mcgraw-hill; 2008.

17. Tabatabaie M, Zahraie M, Ahmadnia H. [Principles of disease prevention and surveillance ]. 1 edTehran: Rohghalam Pub; 2006.

18. Zeynali M, Fayaz A, Nadim A. Animal bites and rabies: Situation in Iran. Arch Iran Med. 1999;2(3):120-4.

19. Tepsumethanon S, Tepsumethanon V, Wilde H. Risk of rabies after mammal bites in Thai children. J Med Assoc Thai. 2002;85(1):77-81.

20. Singh J, Jain DC, Bhatia R, Ichhpujani RL, Harit AK, Panda RC, et al. Epidemiological characteristics of rabies in Delhi and surrounding areas, 1998. Indian Pediatr. 2001;38(12):1354-60.

21. Pancharoen C, Thisyakorn U, Lawtongkum W, Wilde H. Rabies exposures in thai children. Wilderness Environ Med. 2001;12(4):239-43.

22. Moore DA, Sischo WM, Hunter A, Miles T. Animal bite epidemiology and surveillance for rabies postexposure prophylaxis. J Am Vet Med Assoc. 2000;217(2):190-4.

23. Matter HC, Wandeler AI, Neuenschwander BE, Harischandra LP, Meslin FX. Study of the dog population and the rabies control activities in the Mirigama area of Sri Lanka. Acta Trop. 2000;75(1):95-108.

24. Falahian V. [Mortality survey of rabies in Iranian Pasteur Institute]. J Nabz. 1994;4(3):28-38.

25. Sadeghi A, Shariatzadeh MR, Nezhadrahim R. [Study of incidence of animal bites in West Azarbaijan Province of Iran in 1999]. Urmia Med J. 2003;14(1):40-5.

26. Oginni FO, Akinwande JA, Fagade OO, Arole GF, Odusanya SA. Facial dog bites in Southwestern Nigerian children: an analysis of eight cases. Trop Doct. 2002;32(4):239-40.

27. Rezaeinasab M, Rad I, Bahonar AR, Rashidi H, Fayaz A, Simani S, et al. The prevalence of rabies and animal bites during 1994 to 2003 in Kerman province, southeast of Iran. Iranian J Vet Res. 2007;8(4):343-50.

28. Kassiri H, Kassiri A, Lotfi M, Shahkarami B, Hosseini SS. Animal bite incidence in the County of Shush, Iran.J Acute Dis. 2014:26-30.

29. Kassiri H, Kassiri A, Mosavi R, Jashireh A, Lotfi M. Prevalence rate and epidemiological determinants of animal bite in Ahvaz County, Khuzestan Province, Southwestern Iran. J Acute Dis. 2014;51:55.

30. Kassiri H, Kassiri A, Pourpolad Fard M, Lotfi M. The prevalence of animal bite during 2004-2008 in Islamabad-Gharb County, Kermanshah Province, Western Iran. Asian Pac J Trop Dis. 2014;4(4 suppl 1):S342-6. 